\title{
Very Short-Term Surface Solar Irradiance Forecasting Based on FengYun-4 Geostationary Satellite
}

\author{
Liwei Yang ${ }^{1}$, Xiaoqing Gao ${ }^{1, *}{ }^{\mathbb{C}}$, Jiajia Hua ${ }^{2,3}$, Pingping $\mathrm{Wu}^{4}$, Zhenchao $\mathrm{Li}^{1}$ and Dongyu Jia ${ }^{5}$ \\ 1 Key Laboratory of Land Surface Process and Climate Change in Cold and Arid Regions/Northwest Institute \\ of Eco-Environment and Resources, Chinese Academy of Sciences, Lanzhou 730000, China; \\ yanglw@lzb.ac.cn (L.Y.); zhenchaoli@lzb.ac.cn (Z.L.) \\ 2 Tangshan Meteorological Service/CMA, Tangshan 063000, China; ustchuajiajia@163.com \\ 3 Key Laboratory of Meteorology and Ecological Environment of Hebei Province, Shijiazhuang 050000, China \\ 4 Weichang Manchu Mongolia Autonmous County Meteorological Bureau/CMA, Chengde 068450, China; \\ wc54311wpp@163.com \\ 5 College of Geography and Environmental Engineering, Lanzhou City University, Lanzhou 730070, China; \\ jdy890719@1zb.ac.cn \\ * Correspondence: xqgao@lzb.ac.cn; Tel.: +86-0931-4967110
}

Received: 26 March 2020; Accepted: 30 April 2020; Published: 3 May 2020

check for updates

\begin{abstract}
An algorithm to forecast very short-term (30-180 min) surface solar irradiance using visible and near infrared channels (AGRI) onboard the FengYun-4A (FY-4A) geostationary satellite was constructed and evaluated in this study. The forecasting products include global horizontal irradiance (GHI) and direct normal irradiance (DNI). The forecast results were validated using data from Chengde Meteorological Observatory for four typical months (October 2018, and January, April, and July 2019), representing the four seasons. Particle Image Velocimetry (PIV) was employed to calculate the cloud motion vector (CMV) field from the satellite images. The forecast results were compared with the smart persistence (SP) model. A seasonal study showed that July and April forecasting is more difficult than during October and January. For GHI forecasting, the algorithm outperformed the SP model for all forecasting horizons and all seasons, with the best result being produced in October; the skill score was greater than $20 \%$. For DNI, the algorithm outperformed the SP model in July and October, with skill scores of about $12 \%$ and $11 \%$, respectively. Annual performances were evaluated; the results show that the normalized root mean square error (nRMSE) value of GHI for $30-180$ min horizon ranged from 26.78 to $36.84 \%$, the skill score reached a maximum of $20.44 \%$ at the 30-min horizon, and the skill scores were all above 0 for all time horizons. For DNI, the maximum skill score was $6.62 \%$ at the 180-min horizon. Overall, compared with the SP model, the proposed algorithm is more accurate and reliable for GHI forecasting and slightly better for DNI forecasting.
\end{abstract}

Keywords: solar energy; FengYun-4A satellite; solar power plant; surface solar irradiance; forecast

\section{Introduction}

The rapid growth of global energy demands has posed serious challenges for the realization of sustainable economic and social development after entering the 21st century. As the largest clean and renewable energy source on earth, solar energy is expected to become the largest power source in the world in the future. The cost of solar panels and related devices has declined dramatically, creating the conditions for large-scale research and application of photovoltaic power generation systems in the coming decades [1-3]. Photovoltaic arrays mainly use global solar irradiance to generate output power. Because surface solar irradiance is easily affected by meteorological factors (mainly clouds), the photovoltaic output power fluctuates and changes considerably. With increases in the 
installed power ratio, large fluctuations in the output power have a huge impact on the power grid system, which could have serious and dangerous consequences [4,5]. Therefore, accurate prediction of surface solar irradiance can provide important decision-making support for power dispatching, effectively reducing the operation costs of power systems which depend solely on photovoltaic resources, and produce greater economic and social benefits $[6,7]$.

For different temporal and spatial resolutions of surface solar irradiance predictions, the methods used are also different. Medium- and long-term predictions can be used in the construction and planning of photovoltaic power stations and other fields; climate models from the Coupled Model Intercomparison Project Phase 5 (CMIP5) under different scenarios are most commonly used $[8,9]$. Short-term predictions can provide hourly variations in surface solar irradiance, and the prediction results can be used in optimal microgrid scheduling. The main algorithms used in this field are numerical weather prediction (NWP) models, statistical methods, and artificial neural networks (ANNs) [10-13]. Very short-term surface solar irradiance forecasting, also called "now-casting" (0-3 h ahead) can provide information about photovoltaic power variation in the high-frequency range, which is mainly used in transient analyses and control strategy research of micro grids. Ground-based sky images and satellite images are mostly used to obtain the cloud motion vectors (CMV) field $[14,15]$. When the forecast horizon is in the range of $0-3 \mathrm{~h}$, the CMV-based method performs better than the NWP model and ANN $[14,16]$.

The objective of this study is very short-term forecasting $(0-3 \mathrm{~h})$ of surface solar irradiance. The spatial-temporal resolution of ground-based cloud images is very high, but the observation range of the all-sky imager is limited (e.g., the effective monitoring range of TSI-880 is $5 \mathrm{~km}$ ). For three-hour-ahead forecasting, the cloud cluster may have moved out of the monitoring range of the imager. Therefore, the all-sky imager is generally suitable for 0-15 min-ahead forecasting. As for the limitations of all-sky imager monitor, a larger range image from the satellite needs to be considered for 0-3 h-ahead forecasting. To a user, e.g., a solar power plant, satellite cloud images are accessible immediately and almost for free on the Internet. Thus, satellite cloud images are inexpensive and can accurately reveal the characteristics of regional cloud cover $[17,18]$.

Satellite observation has been used for surface solar irradiance forecasting in different ways. Arbizu-Barrena, et al. [10] used Meteosat Second Generation (MSG) for short-term solar radiation forecasts (up to six hours ahead) of global horizontal irradiance (GHI) and direct normal irradiance (DNI) by forecasting cloud indices using the Weather Research and Forecasting (WRF) numerical weather prediction (NWP) model. Nonnenmacher and Coimbra [19] used satellite images and ground measurements for very short-term GHI forecasts (1-3 h ahead) with an approach based on an optical flow algorithm to track and advect cloud. Wang, et al. [14] used a MSG geostationary satellite for very short-term GHI and DNI forecasts ( $0-4 \mathrm{~h}$ ahead). Their algorithm was developed using the SEVIRI (imager on MSG) cloud physical properties. Gallucci, et al. [20] used MSG data for nowcasting surface solar irradiance (up to two hours in advance); the approach was based on advection and extrapolation of MSG-SEVIRI channels. Ayet and Tandeo [21] used MSG satellite images for nowcasting solar irradiance (up to six hours ahead) of GHI; they statistically emulated cloud dynamics, and no numerical weather model was required. Rosiek, et al. [22] applied MSG satellite observations and ANN for online three-hour forecasting of GHI and the building integrated photovoltaic (BIPV) power output.

The aforementioned studies show that MSG is the most widely-used satellite for short-term solar irradiance forecasting. FengYun-4A (FY-4A) is a new generation of geostationary meteorological satellite for quantitative applications in China. It provides high resolution earth observations of geosynchronous orbit in China and is equipped with an advanced geosynchronous radiation imager (AGRI) which can obtain 14-band channels of the earth's cloud images at high frequency. Compared with the FengYun-2 radiation imager, AGRI's observation performance is considerably better [23,24]. FY-4A satellite images have rarely been used for surface solar irradiance nowcasting [25]. Therefore, we conducted this study on surface solar irradiance nowcasting based on FY-4A satellite images, which has profound significance for the system safety of photovoltaic power stations and grids in China. 
In this work, we developed and evaluated an algorithm to forecast very short-term (30-180 min) surface solar irradiance using visible and near infrared (AGRI) channels on board the FY-4A geostationary satellite. The forecasting products of surface solar irradiance include GHI and DNI. The European Solar Radiation Atlas (ESRA) model [26] was used to calculate the surface solar irradiance under clear sky conditions. As a solar irradiation attenuation model, we used the Heliosat-2 method [27]. Particle image velocimetry (PIV) was used to obtain the cloud motion vector (CMV) field from the satellite images. The GHI and DNI forecast results were assessed using ground-based measurements at the Weichang meteorological station in Chengde of four typical months (October 2018, and January, April, and July 2019) under all sky conditions. Finally, the FY-4A satellite-based method was compared with the classical smart persistence (SP) model.

In this algorithm, historical data and observed meteorological elements, such as temperature, wind speed, and so on, are not required. Many forecasting methods with high precision are available in this field, but they require more meteorological variables, high quality data, complex calculations, a high performance computer, etc., which is costly and inconvenient for industrial application. Our algorithm has lower computational cost and it is applicable in areas where a meteorological observation network system is not always available.

The paper is structured as follows: Section 2 describes the observation data including satellite observations and ground measurements. In Section 3, we present the surface solar irradiance forecasting algorithm and model performance metrics. In Section 4, the GHI and DNI forecast results are presented and evaluated. In Section 5, the conclusions and discussion are outlined.

\section{Measurements}

\subsection{Satellite Images}

FengYun-4, a new generation of Chinese geostationary meteorological satellite, was successfully launched on 11 December, 2016. It is equipped with an advanced geosynchronous radiation imager (AGRI) which has 14 channels between 0.47 and $13.5 \mu \mathrm{m}$; the spatial resolution is $0.5-4 \mathrm{~km}$. The satellite images can be downloaded from: http://satellite.nsmc.org.cn/. Satellite images with a solar elevation angle of less than $12^{\circ}$ are not used (i.e., the measurement error of the instrument caused by the shielding of the surrounding mountains and calculation error caused by the low brightness of the satellite images). In this study, the visible $(0.63-0.69 \mu \mathrm{m})$ and near infrared $(0.76-0.9 \mu \mathrm{m})$ channels were used for cloud observation (identify cloudy groups for cloud index derivation and CMV calculation). Images from FY-4A were captured from August 2018 to September 2019 with a $2 \times 2 \mathrm{~km}$ spatial resolution. Figure 1 shows that solar irradiance fluctuates considerably due to the movement of clouds.

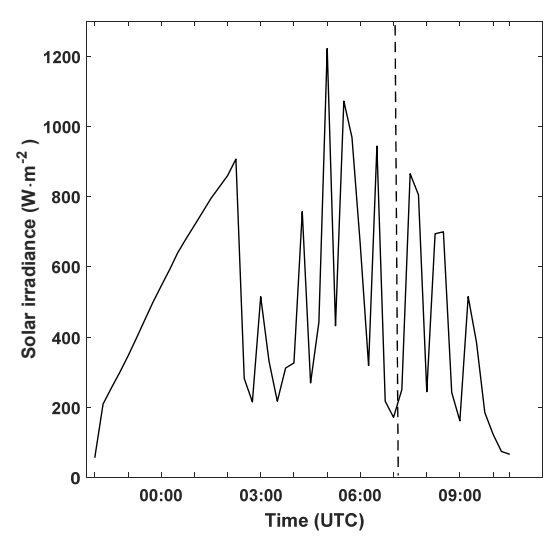

(a)

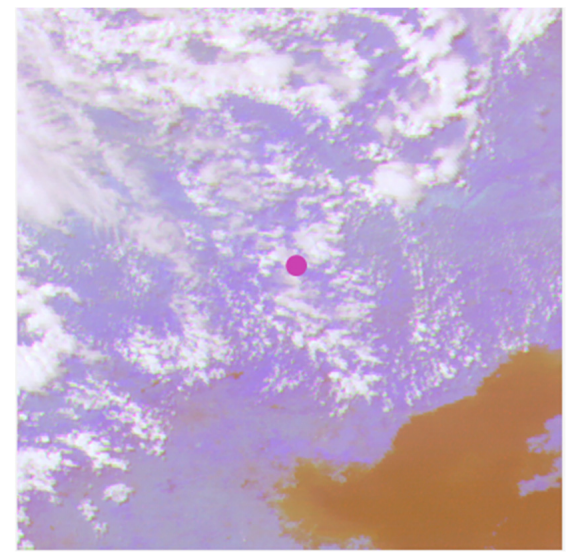

(b)

Figure 1. Example of variation curve of the global horizontal irradiance (GHI) measurement at meteorological station in Chengde on 1 July 2019 (a) and time-matched FY-4A satellite images on 1 July, 2019 at 07:15 UTC (b). The red point is the location of the ground observation station. 


\subsection{Ground-Based Observations}

The Beijing-Tianjin-Hebei (BTH) region is an important energy consumption area, accounting for more than $10 \%$ of the total energy consumption in China. Due to the increasingly serious pollution problem in this area, developing clean energy has become a key direction for energy transition [28].

The city of Chengde is located in the BTH region. Due to the unique natural and geographical conditions, Chengde has a variety of clean energy types and rich resources, and has become a national new energy demonstration city. The Chengde climate is temperate continental monsoon, with four distinctive seasons. The altitude in Chengde is $200-1200 \mathrm{~m}$. The average annual temperature is $5.6^{\circ} \mathrm{C}$, the average annual precipitation is $300-560 \mathrm{~mm}$, and the average annual sunshine is $2845 \mathrm{~h}$.

The observation data of global horizontal irradiation (GHI), direct normal irradiance (DNI), and diffuse horizontal irradiation (DHI) were provided by the Weichang national basic meteorological station in Chengde (Station No.: 54311). The geographical location is shown in Figure $2\left(117^{\circ} 45^{\prime} 58^{\prime \prime} \mathrm{E}\right.$, $41^{\circ} 57^{\prime} 38^{\prime \prime} \mathrm{N}$; altitude $\left.892.7 \mathrm{~m}\right)$. The solar irradiance data are measured at a 1-min time resolution. The GHI and DNI are recorded using FS-S6 and FS-D1 solar radiation sensor, respectively. The instruments are calibrated every two years, conforming to the First Class technical indicators of the ISO 9060:1990 and WMO standards.

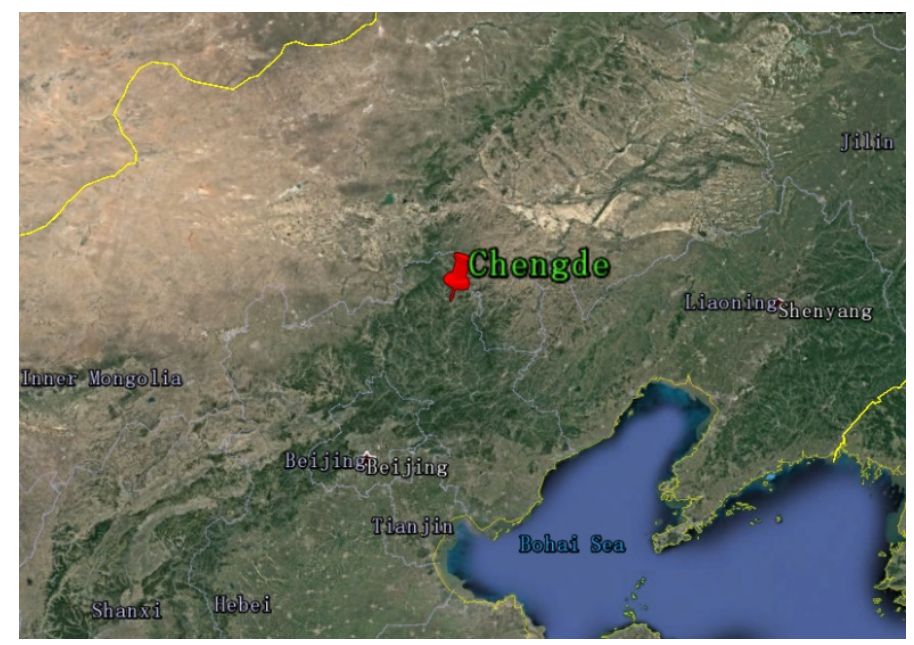

Figure 2. Location of the meteorological station of Chengde (from Google Earth).

\section{The Description of Forecasting Methods}

\subsection{ESRA Model}

The accuracy of the clear sky radiative model directly impacts the solar irradiance forecast results. Many validation studies have been conducted to compare the accuracy, advantages, and limitations of each clear sky radiative model [29-33]. In this work, we selected a clear sky model with high precision both for GHI and DNI data and low complexity. After a detailed investigation, we selected the European Solar Radiation Atlas (ESRA) model to calculate the surface solar irradiance. The method details can be found in the literature [26]. The calculation of the Linke turbidity factor $\left(T_{\mathrm{L}}\right)$ is the critical input for the accuracy of the model. The $T_{\mathrm{L}}$ in this work was calculated using the following equation [34]:

$$
T_{L}=3.91 \tau_{550} \exp \left(0.689 \times \frac{1013.25}{p}\right)+0.376 \ln \left(u_{\mathrm{H}_{2} \mathrm{O}}\right)+\left[2+0.54 \frac{1013.25}{p}-0.5\left(\frac{1013.25}{p}\right)^{2}+0.16\left(\frac{1013.25}{p}\right)^{3}\right]
$$

where $\tau_{550}$ is the aerosol optical depth (AOD) at $550 \mathrm{~nm}$ (dimensionless), $u_{\mathrm{H}_{2} \mathrm{O}}$ is the atmospheric precipitable water value (pwv; $\mathrm{mm}$ ), and $p$ is the local atmospheric pressure (hPa).

In this work, the pwv data were collected from the Chengde meteorological station (monitoring GPS/MET moisture observation station data); the value acquired was from the most recent time 
(according to the time horizon) for the present day. The AOD values were acquired from monthly averaged data [35-37]; the values for October, January, April, and July were 0.03, 0.04, 0.09, and 0.14, respectively. Heavy pollution days with an air quality index (AQI) greater than $120 \mu \mathrm{g} / \mathrm{m}^{3}$ were not considered. Using this method to calculate $T_{\mathrm{L}}$, the normalized root mean square deviation (nRMSE) of the ESRA clear sky model was found to be $3.1 \%$ for GHI and $5.6 \%$ for DNI based on the days under clear sky conditions in this work. For example purposes, the measured and forecast solar irradiances under clear sky condition are presented in Figure 3 for one day each ( 1 min time resolution) in April and September. The GHI and DNI components were considered in this study.
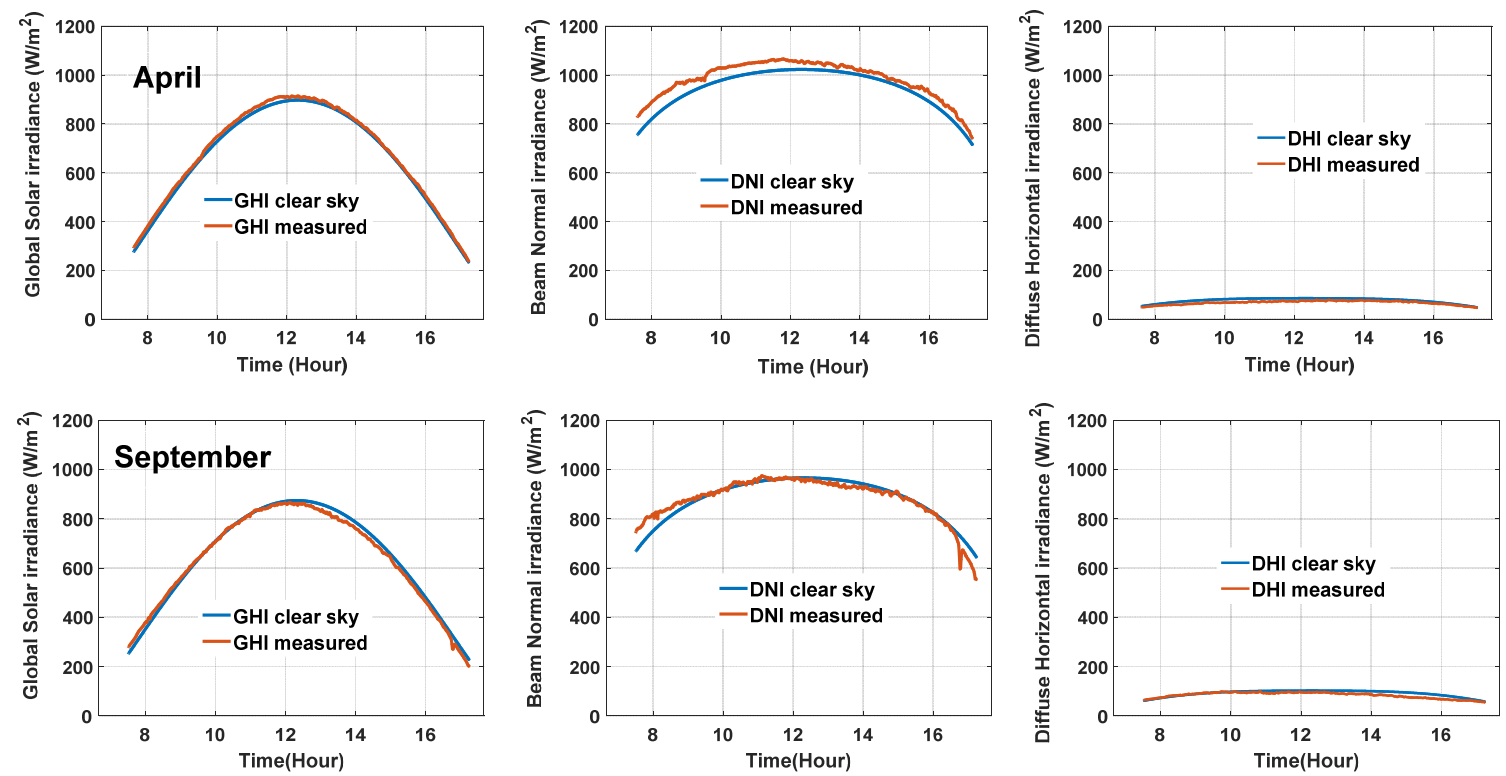

Figure 3. The ground measured and forecast results of GHI, DNI, and DHI under clear sky conditions for one day: 2 April (top) and 8 September (bottom), 2019.

Better turbidity estimation is crucial for improving the accuracy of the clear sky model. Highly accurate retrieval of aerosol optical thickness (AOD) is the challenge. Retrieving high-resolution AOD using the FY-4A satellite has been researched [38-40]. The retrieved high-resolution AOD is very important for the BTH region we studied, as photovoltaic plants are developing rapidly but are also facing problems due to air pollution. As such, retrieving AOD data using the FY-4A satellite to improve the accuracy of the ESRA algorithm will be our next work.

\subsection{The Heliosat-2 Method}

As a solar irradiation attenuation model, we used is the Heliosat-2 method [27]. The model has been applied to study the attenuation of solar irradiation reaching the ground using satellite images, and to forecast the surface solar irradiation [10,22,41-44]. The general idea of the physical model involves converting the satellite observation pixel image into a cloud index pixel image, and multiplying the cloud index with solar irradiation using the clear sky model. Then, the surface irradiation at any given location (pixels) can be obtained.

The attenuation caused by meteorological factors in the atmosphere is obtained by $K_{c}$, which is calculated using the following formula:

$$
\begin{cases}n^{t}(i, j)<-0.2, & K_{c}=1.2 \\ -0.2<n^{t}(i, j)<0.8, & K_{c}=1-n^{t}(i, j) \\ 0.8<n^{t}(i, j)<1.1, & K_{c}=2.0667-3.6667 n^{t}(i, j)+1.667\left(n^{t}(i, j)\right)^{2} \\ n^{t}(i, j)>1.1 & K_{c}=0.05\end{cases}
$$


where $K_{c}$ is the clear sky index (dimensionless), and $n^{t}(i, j)$ is the cloud index (dimensionless) at the instant time $t$ and pixel $(i, j)$. Its value is obtained using Equation (3):

$$
n^{t}(i, j)=\frac{\rho^{t}(i, j)-\rho_{g}{ }^{t}(i, j)}{\rho_{c}^{t}(i, j)-\rho_{g}{ }^{t}(i, j)}
$$

where $\rho^{t}(i, j)$ is the apparent albedo (dimensionless), $\rho_{g}{ }^{t}(i, j)$ is the apparent albedo of the ground under clear sky conditions (dimensionless), and $\rho_{c}{ }^{t}(i, j)$ is the apparent albedo of the brightest clouds (dimensionless). The FY-4A satellite level 1 data provide a digital number which can be directly converted to apparent albedo after looking it up in the calibration table. To find the albedo of the brightest clouds and the ground for each pixel, a histogram of all pixels throughout a year is constructed through statistical analysis. The 95th percentile of the histogram was selected as the albedo of the brightest clouds, while the darkest pixels from its monthly time series were selected as the ground albedo.

The DNI estimation method can be found in [45], which is based on the diffuse fraction model by Skartveit, et al. [46].

$$
D N I=D N I_{c s} \times\left(K_{c}-0.38 \times\left(1-K_{c}\right)\right)^{2.5}
$$

When the clear sky index $K_{c}$ is smaller than 0.35 , the DNI value is set to zero.

\subsection{Forecasting Model Process}

The cloud index and clear-sky index pixels were obtained using the Heliosat-2 method. The particle image velocimetry (PIV) algorithm can record a large amount of velocity distribution information at the transient point and provide the spatial structure and flow characteristics of the velocity field. The MPIV is a PIV toolbox written in MATLAB; the detailed method is described in [47], and the full package of the MPIV toolbox can be downloaded free of charge. Here, MPIV was used to calculate the cloud velocity vector for forecasting the clear sky index, which will move to pixels (the area in which we were interested) in the future. To guarantee that the fastest-moving cloud will not move out of the area being studied, the FY-4A satellite cloud image pixel area was selected as $400 \times 400$ pixels, with the research pixel in the center. The latest two consecutive satellite images were used. In the MPIV method, the area of the square portion needs to be set to find the most similar and the same-sized portion in the continuous image to obtain the cloud motion vector (CMV) of the selected square portion. The corresponding MPIV criterion to search for the best match block was set to the minimum quadratic difference (MDQ) method. In this work, we selected the square portion as $32 \times 32$ pixels, and overlapping was not allowed. To ensure the accuracy of the results, filtering (global filter) was applied and unrealistic vectors were removed. An interpolation algorithm (weighted averaging of adjacent pixel value) was used to replace the invalid values. Then, the cloud velocity field was obtained. Finally, we obtained a value of the clear sky index for the area of interest with different time horizons. The time horizons in this work were set to $30,60,90,120,150$, and $180 \mathrm{~min}$.

The surface solar irradiances were obtained by multiplying the clear sky index by the clear sky irradiances. The main GHI and DNI forecasting process steps are summarized in Figure 4. The time horizons ranged from 30 to $180 \mathrm{~min}$; for example, a time horizon of $30 \mathrm{~min}$ indicates a 30 -min-ahead forecasting process. The MATLAB 2016b mathematic software was employed to model the forecasting algorithm. 


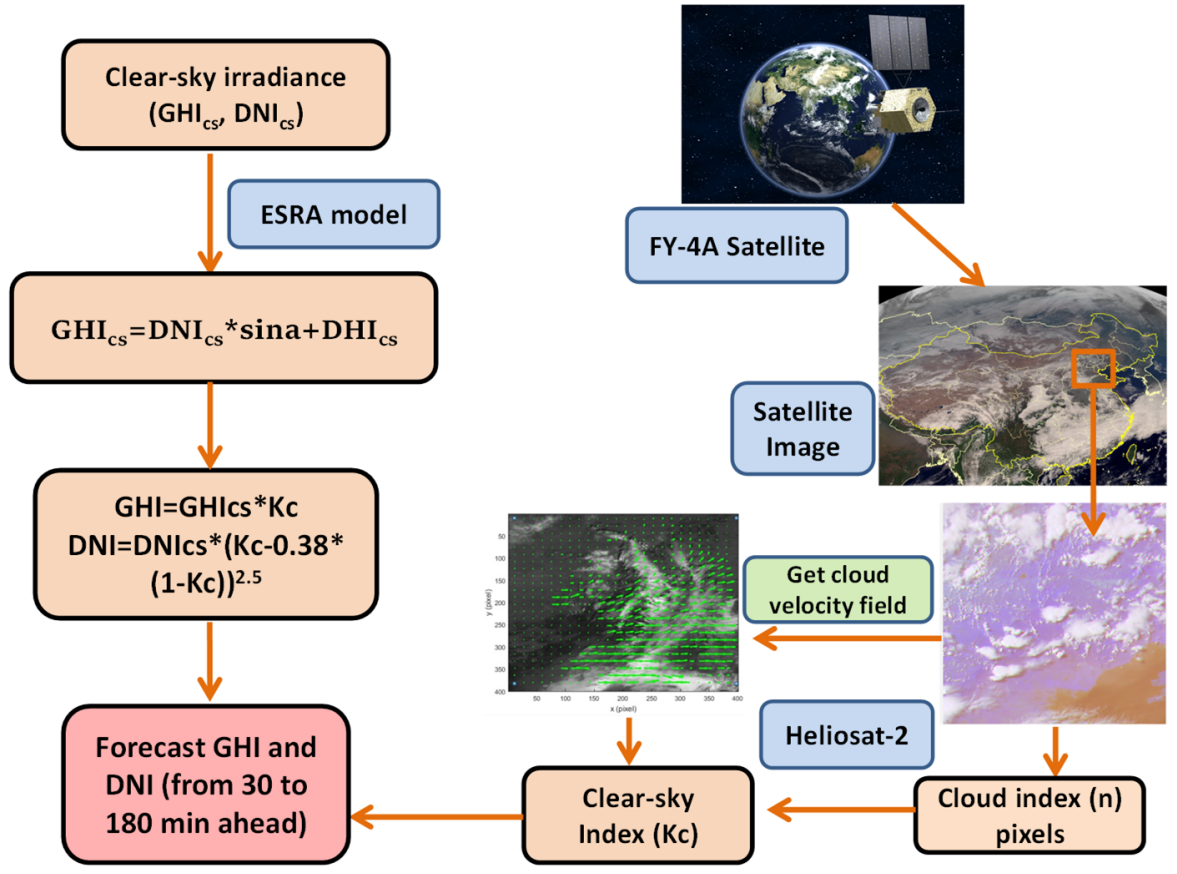

Figure 4. Overview of GHI and DNI forecast process with time horizons of 30 to $180 \mathrm{~min}$.

\subsection{Performance Metrics}

It is meaningless to simply compare models. Each model has its own applicable scenarios, advantages, and disadvantages. To evaluate the quality of the model, it needs to be placed in a specific data scenario. Real data must be used to determine which model is better in an applied scenario. Therefore, common error metrics were employed to evaluate the performance of the solar forecasting algorithm: root mean square error (RMSE), mean absolute error (MAE), mean bias error (MBE), the correlation coefficient $(R)$, and the normalized RMSE (nRMSE), MAE (nMAE), and MBE (nMBE), which are defined as [48]:

$$
\begin{gathered}
R M S E=\sqrt{\frac{1}{N} \times \sum_{i=1}^{N}\left(y_{i}-x_{i}\right)^{2}} \\
n R M S E=\frac{R M S E}{\bar{x}} \times 100 \% \\
M A E=\frac{1}{N} \times \sum_{i=1}^{N}\left|y_{i}-x_{i}\right| \\
n M A E=\frac{M A E}{\bar{x}} \times 100 \% \\
M B E=\frac{1}{N} \times \sum_{i=1}^{N}\left(y_{i}-x_{i}\right) \\
R=\frac{n M B E=\frac{M B E}{\bar{x}} \times 100 \%}{\sqrt{\sum_{i=1}^{N}\left(x_{i}-\bar{x}\right)\left(y_{i}-\bar{x}\right)} \sqrt{\sum_{i=1}^{N}\left(y_{i}-\bar{y}\right)}}
\end{gathered}
$$


where $x$ is the ground measured value, $y$ is the forecasted value, and $N$ is the number of data.

\subsection{Forecast Skill}

We used a new metric, the forecast skill score (SS), which is expressed as [49,50]:

$$
S S=1-\frac{n R M S E_{\text {forecast }}}{n R M S E_{\text {persistence }}}
$$

where $n R M S E_{\text {forecast }}$ is the nRMSE value for the solar forecasting algorithm, and $n R M S E_{\text {persistence }}$ is the nRMSE value for the smart persistence (SP) model. The SP model is defined as [51]:

$$
\hat{y}(t+\tau)=y(t) \times \frac{y^{c l r}(t+\tau)}{y^{c l r}(t)}
$$

where $\hat{y}(t+\tau)$ is the solar irradiance forecasting value at time $t, y(t)$ is the ground measured value, $y^{c l r}(t)$ is the value of solar irradiance calculated from the clear sky model (ESRA in this work) at time $t$, and $\tau$ is the forecast horizon (30-180 $\mathrm{min}$ in this work). For the SP model, only the ground measured irradiances and the clear sky irradiances are needed, and the key consideration is the current measured deviation of the irradiances from clear sky irradiances. Although the SP model is simple, it is accurate for the prediction of periods with low GHI (or DNI) variability. This smart persistence model mainly served as a reference model; therefore, the predicted results of any forecast model being better than the SP model indicates improvement in the ability to predict random variability [52].

When the forecast skill score (SS) was 1, the algorithm produced perfect forecast results over the reference model; when the SS was 0 , there was no improvement against the reference model; and when the SS was a negative value, the performance of forecast algorithm was worse than the reference.

\section{Results and Discussion}

It's interesting to analyze the accuracy of the model by season (typical months) under all sky conditions, so as to analyze the impact of the meteorological conditions in four seasons on the performances of the models.

\subsection{Seasonal Studies}

\subsubsection{Global Horizontal Solar Irradiation: GHI}

The all-sky conditions considered here refer to clear, partly cloudy, and overcast skies. The RMSE is related to the average value of each season. Comparing the accuracy of the model in different seasons using RMSE or MAE is difficult, so we used the nRMSE and nMAE to analyze the performance of the models. Figure 5; Figure 6 shows the nRMSE and nMAE values of the forecasting models for GHI and DNI in four typical months (October 2018; January, April, and July 2019) at the study location. The figures show that the best results for GHI for both models were produced in January for all forecasting horizons, followed by October; the worst results were produced in July due to the relatively higher number of sunny days in winter but more cloudy days, as well as complicated cloud types and higher aerosol concentrations in summer. Higher aerosol concentrations decrease the accuracy of the clear sky model. Different cloud types have different cloud microphysical properties, which include total cloud cover, cloud optical thickness, cloud equivalent temperature, liquid water column content in cloud, ice water column content in cloud, water particle radius, ice particle equivalent radius, etc. [53,54]. When there are more types of clouds and they change quickly, the GHI fluctuates considerably with no regularity, making the GHI difficult to forecast. In terms of the comparison of nRMSE values, the model using the FY-4A satellite images outperformed the SP model for all forecasting horizons and all seasons. 


\subsubsection{Direct Normal Solar Irradiance (DNI)}

The best results for DNI for both models were produced in October for all forecasting horizons, followed by January; the worst results were produced in July. The predicted results for DNI were significantly worse than for GHI for both models. The DNI prediction is very complicated; it is mainly related to the cloud moisture content, cloud height, cloud shape, dust in the atmosphere, and aerosol content. The daily fluctuation in the DNI component was often remarkable; the measured fluctuations in DNI ranged from a few hundred $\mathrm{W} / \mathrm{m}^{2}$ to almost zero in minutes or seconds. The wide fluctuations in DNI mainly occurred due to its sensitivity to the variation in cloud cover. These steep fluctuations make predictions difficult. The model using FY-4A satellite images outperformed the SP model in July and October, with no improvement against the SP model in April, and slightly worse performance than the SP model in January.
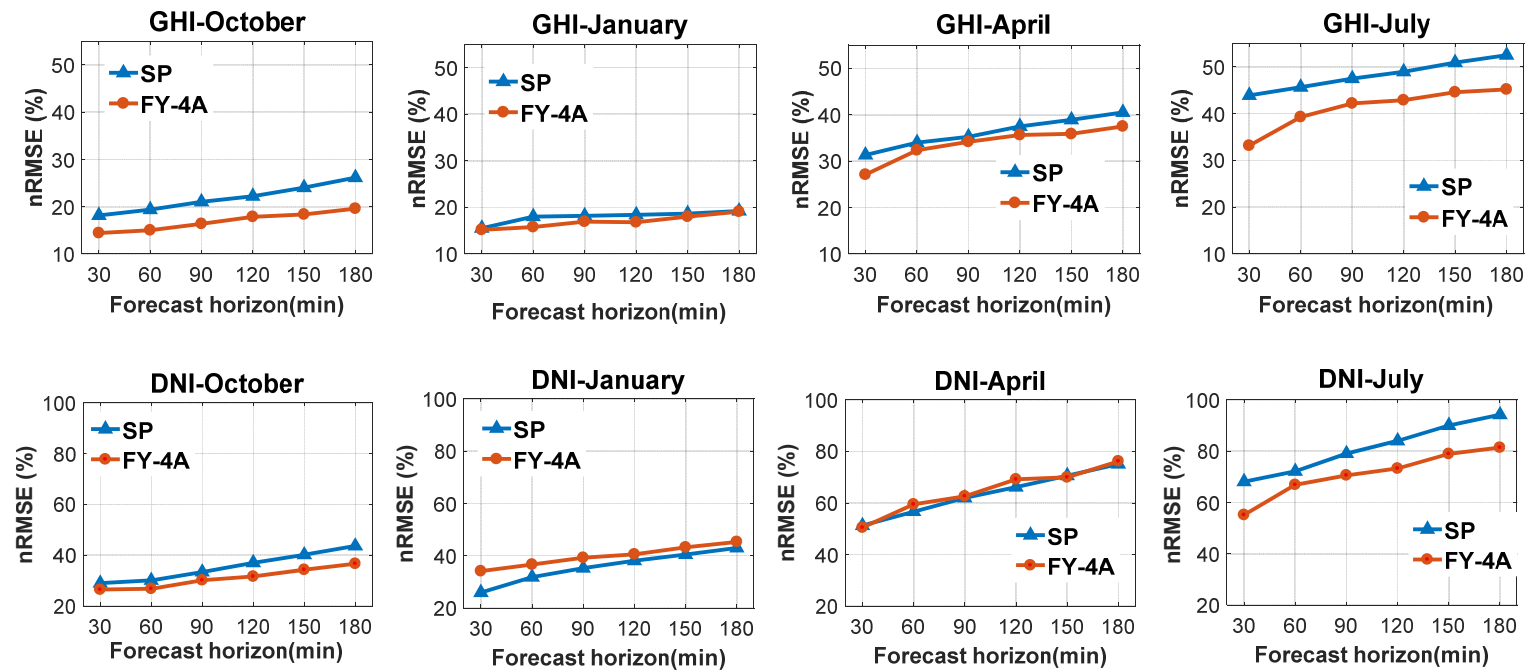

Figure 5. The nRMSE values of forecasting models for GHI (top) and DNI (bottom) in various forecast horizons in four typical months (October 2018; January, April, and July 2019).
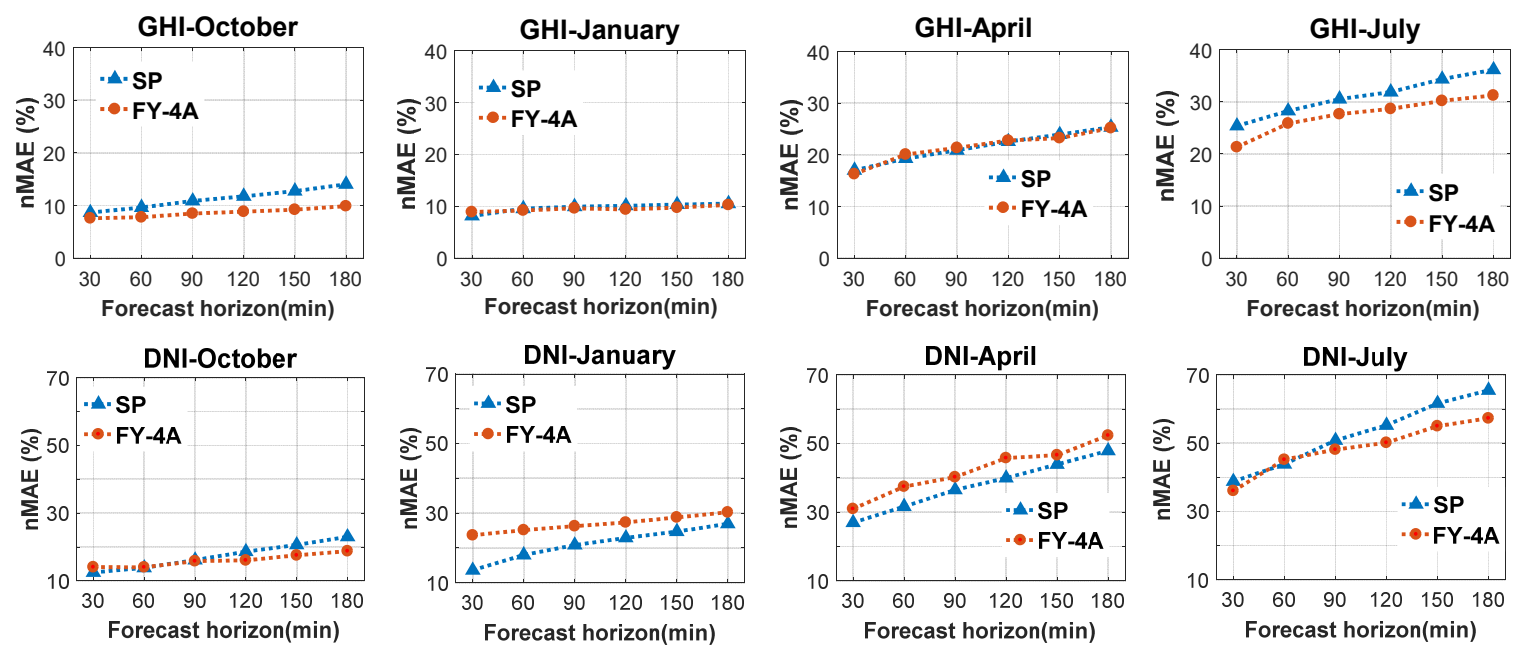

Figure 6. The nMAE values of forecasting models for GHI (top) and DNI (bottom) in various forecast horizon in four typical months (October 2018; January, April, and July 2019).

\subsubsection{Skill Value for GHI and DNI}

Based on Equation (12), the skill (SS) value of the SP model is zero. Figure 7 depicts the skill values for GHI and DNI for various forecast horizons in four typical months. Regardless of the forecast horizon and the season, the values of SS for GHI are all greater than zero. This indicated that the model 
using the FY-4A satellite images outperformed the SP model for all forecasting horizons and seasons; the best result was produced in October, with an SS value greater than $20 \%$, followed by July, with an SS value greater than $10 \%$. In terms of DNI, the SS of the FY-4A satellite model from high to low was July, October, April, and January. The skill value was greater than zero for all forecasting horizons in July and October, with values of about $12 \%$ and $11 \%$, respectively. In April, the SS value was slightly negative. In January, the SS was negative for all forecasting horizons, increasing with increases in the forecasting horizon. This indicated that the model we used for DNI forecasting outperformed the SP model in July and October. The negative SS in January suggests that FY-4A forecasts are not as good as in the other three months.
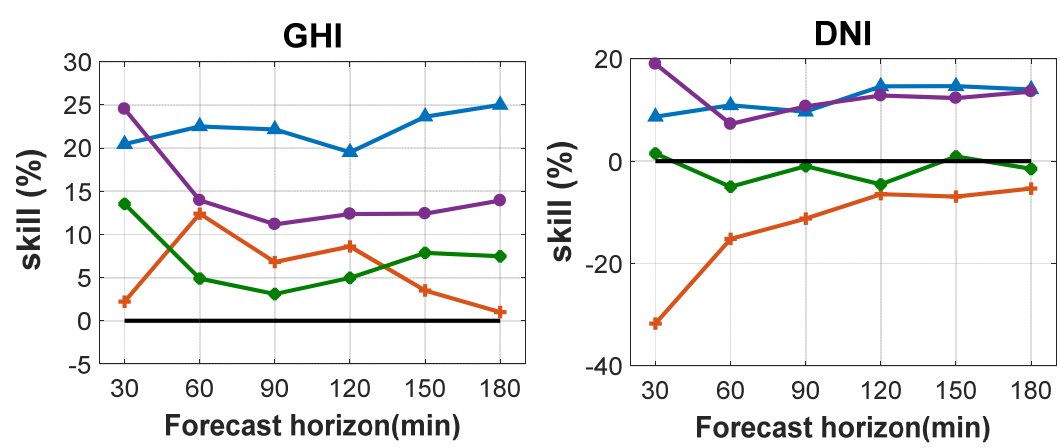

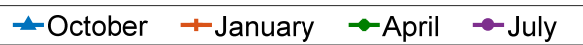

Figure 7. The skill values for GHI (left) and DNI (right) of various forecast horizons in four typical months (October 2018; January, April, and July 2019).

\subsection{Annual Performances}

\subsubsection{Forecast against Ground Measurements: GHI}

The performance of the algorithm was also be visualized using a scatter diagram. Figure 8 shows the GHI values forecasted by the model using FY-4A satellite observations versus ground measured values for the 30- to 180-min time horizon for the four months (October 2018; January, April, and July 2019), totalling about 4019 forecasting time points. The scatter diagram depicts the result of each forecast point. Table 1 shows the statistical indexes for GHI values for the 30-180 min time horizon.

The scatter diagrams show that the points are relatively concentrated, but become more scattered with the increase in time horizon. More discrete points appear in the peak and valley periods. The model using FY-4A satellite observations performed best at the 30-min time horizon; the value of nRMSE increases with increasing forecast horizon. Over time, the physical properties of the clouds are more likely to change. The nRMSE values for GHI for 30, 60, 90, 120, 150, and 180 min horizons were $26.78 \%, 31.51 \%, 33.74 \%, 34.73 \%, 35.7 \% 2$, and $36.84 \%$, respectively; the nMAE values of GHI were $14.88 \%, 17.58 \%, 18.76 \%, 19.54 \%, 20.24 \%$, and $21.35 \%$, respectively. The GHI forecasting values were slightly underestimated (negative MBE and nMBE) for 30-150 min horizons and overestimated (positive MBE and $\mathrm{nMBE}$ ) for the $180 \mathrm{~min}$ horizon. The SS value reached a maximum for the $30 \mathrm{~min}$ time horizon, with a value of $20.44 \%$ compared with the SP model. The skill values were all above 0 for all time horizons, confirming that the proposed algorithm is more accurate and reliable than the SP model. A similar conclusion was drawn from the GHI cumulative frequency curves (Figure 9). However, for the minimum and maximum value forecasts, the FY-4A model results were not as good as in other periods. 

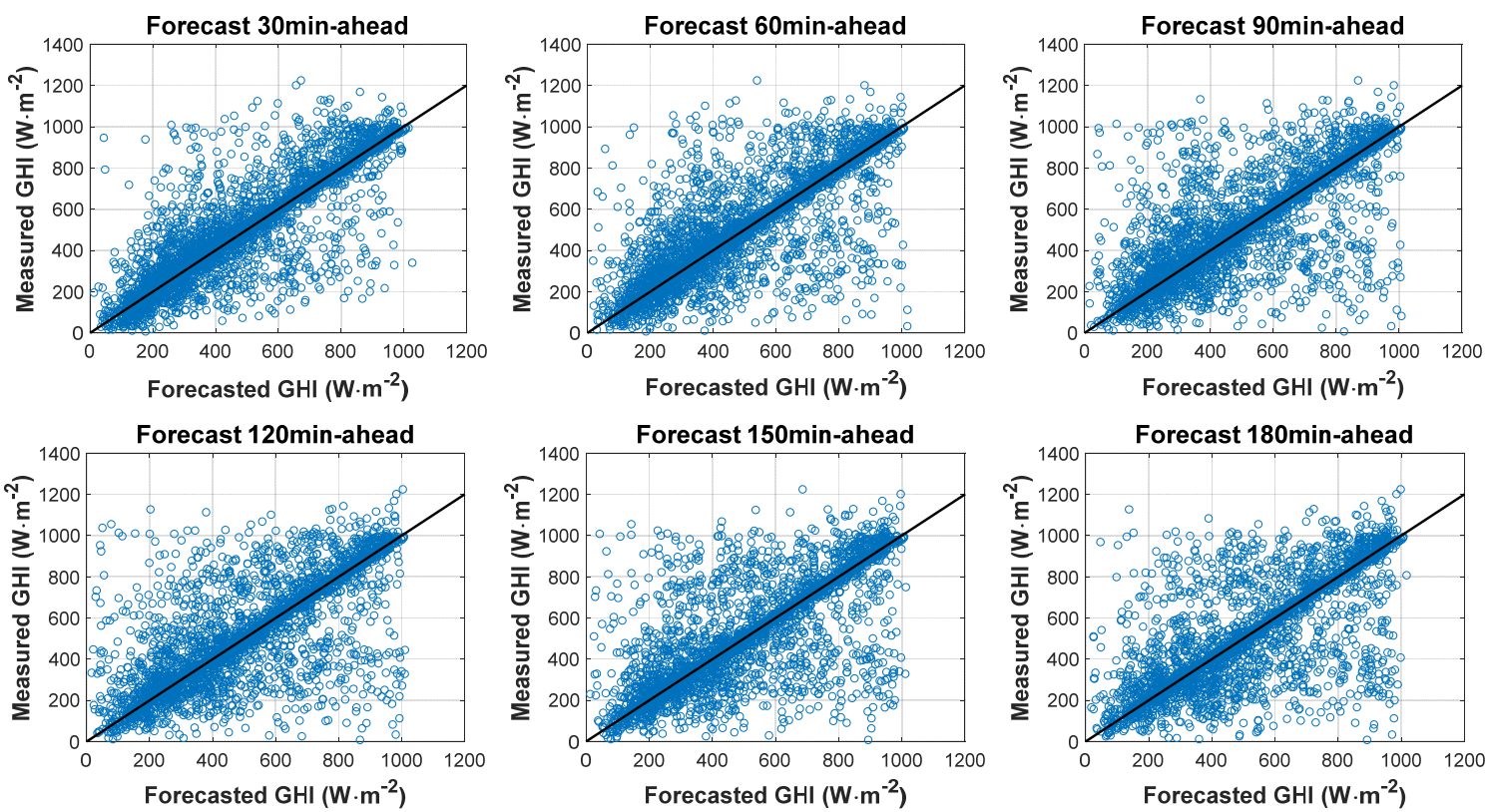

Figure 8. Forecasting GHI values by the model using FY-4A satellite observation versus ground measured values for time horizons from 30 to $180 \mathrm{~min}$.
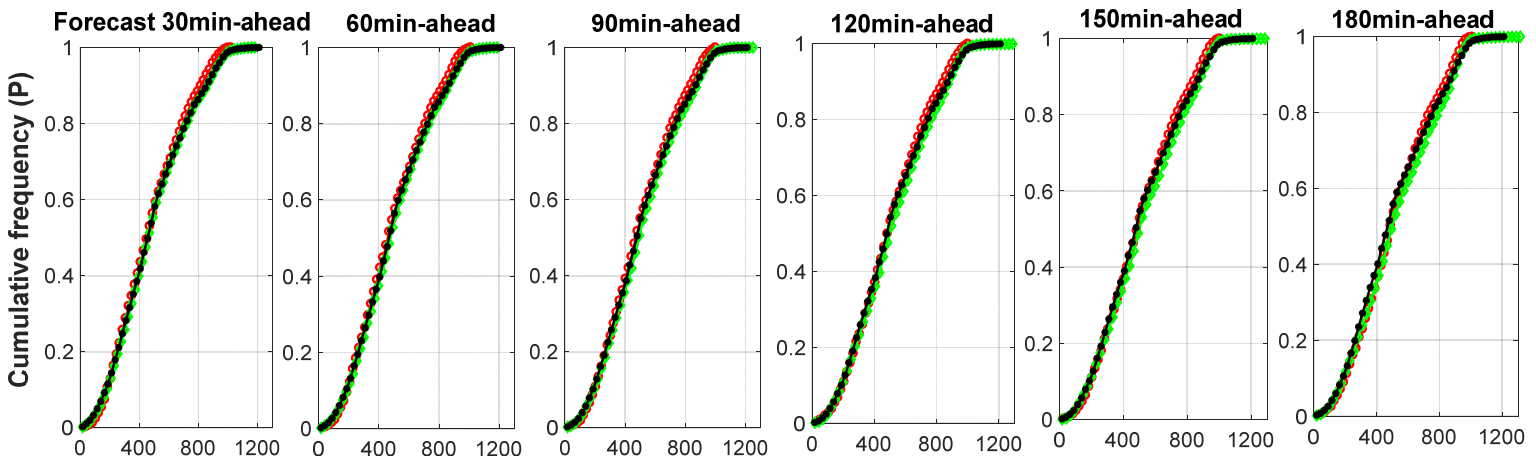

Global solar irradiance $\left(\mathbf{W} \cdot \mathrm{m}^{-2}\right)$

$\rightarrow$ FY-4A forecasted $\rightarrow$ SP forecasted $\rightarrow$ ground measured

Figure 9. The GHI cumulative frequency curves for the time horizons from 30 to $180 \mathrm{~min}$.

\subsubsection{Forecast against Ground Measurements: DNI}

Figure 10 shows the DNI forecasting values versus ground measured values for the time horizon from 30 to $180 \mathrm{~min}$ for the four months. Figure 11 depicts the DNI cumulative frequency curves. Table 2 lists statistical indexes for the DNI value for the 30-180 min time horizon. The nRMSE values for DNI for the FY-4A satellite observation model for 30, 60, 90, 120, 150, and $180 \mathrm{~min}$ horizons were 40.96\%, $46.98 \%, 50.03 \%, 53.04 \%, 55.81 \%$ and $58.80 \%$, respectively; the DNI nMAE values were $25.33 \%, 29.34 \%$, $31.50 \%, 33.59 \%, 35.72 \%$ and $38.15 \%$ respectively. The DNI forecasting values were overestimated (positive MBE and nMBE) for all horizons. The DNI skill (SS) values for the 30-180 min horizons were $6.20 \%, 0.40 \%, 3.99 \%, 5.05 \%, 6.47 \%$, and $6.62 \%$, respectively. The SS values were all above zero for all time horizons. Therefore, compared with the SP model, the FY-4A forecast model is slightly better.

The DNI prediction performance of the models was less satisfying than for GHI because DNI is very sensitive to meteorological conditions. We observed that the scatter distribution of DNI was more discrete than for GHI. The larger deviation occurred during steep fluctuation periods. Especially in summer, the type, height, and density of clouds change dramatically. Thick, low-altitude clouds, usually liquid water clouds, can cause the DNI to change from its maximum to zero in seconds. In addition, thin high-altitude clouds, usually composed of ice crystals, such as cirrus, when the solar 
elevation angle is above $10^{\circ}-20^{\circ}$, DNI can pass through the thin high-altitude clouds. The aerosol content in summer in our study area is significantly higher than during other seasons. Aerosols account for a very small proportion of the mass in the atmosphere, but have a significant impact on radiation transfer and climate. The scattering coefficient, absorption coefficient, scattering phase function, and their variation with wavelength determine the direct radiative forcing of aerosols [55], but large uncertainties still exist in the estimation of direct radiative force using aerosol. At present, the lack of sufficient aerosol concentration observation data complicates the prediction of direct solar irradiance. So, DNI forecasting is more cmplicated and inaccurate than GHI. In our next study, we will validate the model under different climatic conditions.
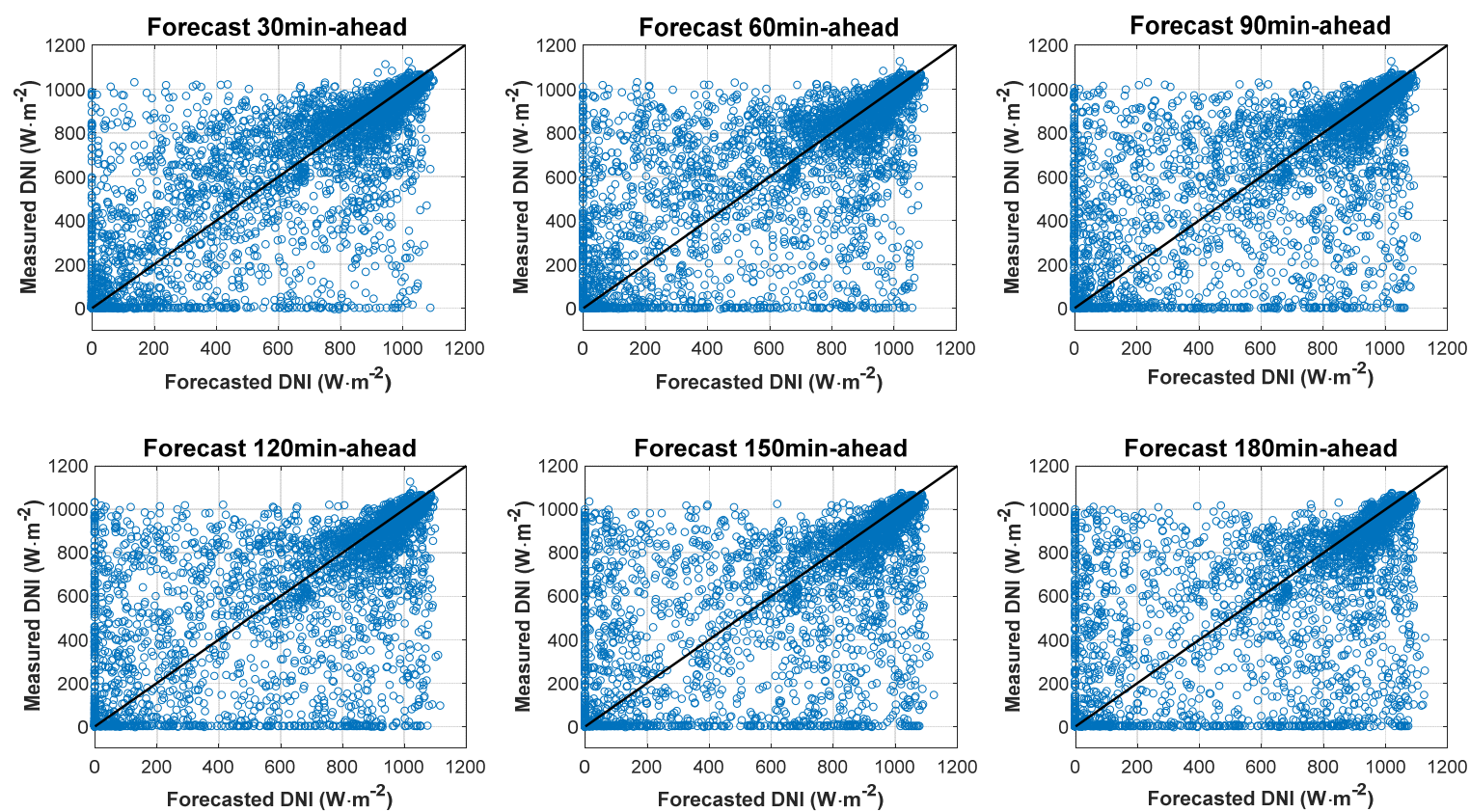

Figure 10. Forecasting DNI values by the model using FY-4A satellite observations versus ground measured values for the time horizon from 30 to $180 \mathrm{~min}$.

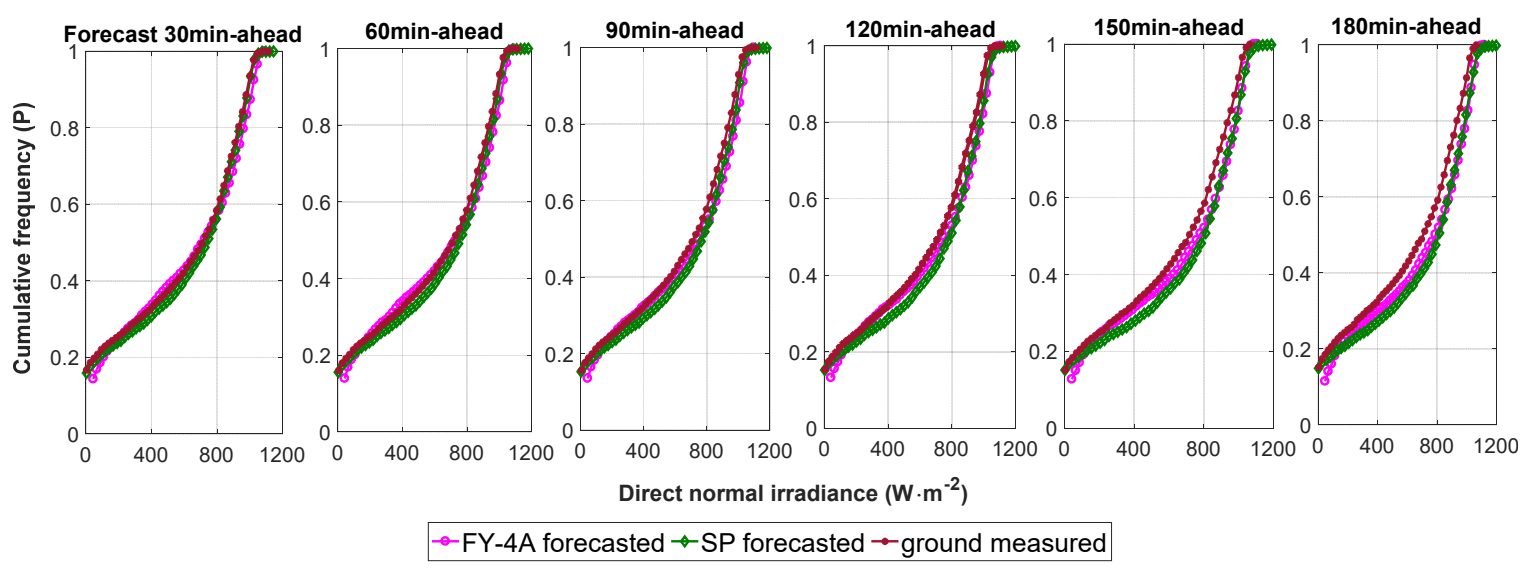

Figure 11. The DNI cumulative frequency curves for time horizons from 30 to $180 \mathrm{~min}$. 
Table 1. Statistical indexes for GHI value from 30 to $180 \mathrm{~min}$ time horizons $\left(\mathrm{W} / \mathrm{m}^{2}\right.$ for mean value, RMSE, MAE, and MBE).

\begin{tabular}{cccccccc}
\hline Metric & Model & $\mathbf{3 0} \mathbf{~ m i n}$ & $\mathbf{6 0} \mathbf{~ m i n}$ & $\mathbf{9 0} \mathbf{~ m i n}$ & $\mathbf{1 2 0} \mathbf{~ m i n}$ & $\mathbf{1 5 0} \mathbf{~}$ in & $\mathbf{1 8 0} \mathbf{~ m i n}$ \\
\hline Mean value & & 493.94 & 504.67 & 511.89 & 516.60 & 517.68 & 514.11 \\
\hline \multirow{2}{*}{ RMSE } & SP & 166.09 & 180.93 & 190.30 & 200.08 & 209.11 & 215.73 \\
& FY-4A & 132.29 & 159.04 & 172.75 & 179.41 & 184.94 & 189.44 \\
\hline \multirow{2}{*}{ nRMSE (\%) } & SP & 33.66 & 35.89 & 37.22 & 38.80 & 40.50 & 42.04 \\
& FY-4A & 26.78 & 31.51 & 33.74 & 34.73 & 35.72 & 36.84 \\
\hline \multirow{2}{*}{ MAE } & SP & 81.96 & 94.58 & 103.26 & 110.03 & 117.65 & 123.41 \\
& FY-4A & 73.54 & 88.75 & 96.07 & 100.95 & 104.81 & 109.79 \\
\hline \multirow{2}{*}{ nMAE (\%) } & SP & 16.61 & 18.76 & 20.20 & 21.34 & 22.79 & 24.05 \\
& FY-4A & 14.88 & 17.58 & 18.76 & 19.54 & 20.24 & 21.35 \\
\hline \multirow{2}{*}{ MBE } & SP & 5.15 & 8.31 & 12.08 & 15.38 & 19.42 & 24.24 \\
& FY-4A & -10.33 & -10.19 & -8.08 & -5.16 & -2.32 & 5.67 \\
\hline \multirow{2}{*}{ nMBE (\%) } & SP & 1.04 & 1.65 & 2.36 & 2.98 & 3.76 & 4.72 \\
& FY-4A & -2.09 & -2.02 & -1.57 & -1.00 & -0.45 & 1.10 \\
\hline \multirow{2}{*}{$R$} & SP & 0.77 & 0.73 & 0.70 & 0.68 & 0.66 & 0.65 \\
& FY-4A & 0.85 & 0.78 & 0.74 & 0.73 & 0.72 & 0.71 \\
\hline \multirow{2}{*}{ SS (\%) } & FY-4A & 20.44 & 12.20 & 9.35 & 10.49 & 11.80 & 12.37 \\
\hline
\end{tabular}

Table 2. Statistical indexes for DNI value for 30-180 min time horizon of the four month $\left(\mathrm{W} / \mathrm{m}^{2}\right.$ for mean value, RMSE, MAE, and MBE).

\begin{tabular}{cccccccc}
\hline Metric & Model & $\mathbf{3 0} \mathbf{~ m i n}$ & $\mathbf{6 0} \mathbf{~ m i n}$ & $\mathbf{9 0} \mathbf{~ m i n}$ & $\mathbf{1 2 0} \mathbf{~ m i n}$ & $\mathbf{1 5 0} \mathbf{~}$ in & $\mathbf{1 8 0} \mathbf{~ m i n}$ \\
\hline \multirow{2}{*}{ Mean value } & & 586.00 & 592.98 & 594.57 & 594.17 & 592.17 & 588.47 \\
\hline \multirow{2}{*}{ RMSE } & SP & 255.55 & 284.52 & 308.61 & 331.11 & 352.76 & 370.41 \\
& FY-4A & 240.01 & 278.61 & -296.76 & 315.33 & 330.51 & 346.05 \\
\hline \multirow{2}{*}{ nRMSE (\%) } & SP & 43.67 & 47.17 & 52.11 & 55.86 & 59.67 & 62.97 \\
& FY-4A & 40.96 & 46.98 & 50.03 & 53.04 & 55.81 & 58.80 \\
\hline \multirow{2}{*}{ MAE } & SP & 130.71 & 156.67 & 178.39 & 196.53 & 215.94 & 231.97 \\
& FY-4A & 148.43 & 173.99 & 186.87 & 199.70 & 211.52 & 224.51 \\
\hline \multirow{2}{*}{ nMAE (\%) } & SP & 22.34 & 26.53 & 30.12 & 33.16 & 36.53 & 39.43 \\
& FY-4A & 25.33 & 29.34 & 31.50 & 33.59 & 35.72 & 38.15 \\
\hline \multirow{2}{*}{ MBE } & SP & 20.02 & 27.96 & 38.14 & 47.85 & 59.69 & 73.37 \\
& FY-4A & 5.51 & 5.34 & 16.68 & 22.52 & 36.02 & 50.39 \\
\hline \multirow{2}{*}{ nMBE (\%) } & SP & 3.42 & 4.73 & 6.44 & 8.07 & 10.10 & 12.47 \\
& FY-4A & 0.94 & 0.90 & 2.81 & 3.79 & 6.08 & 8.56 \\
\hline \multirow{2}{*}{$R$} & SP & 0.77 & 0.72 & 0.67 & 0.62 & 0.58 & 0.54 \\
& FY-4A & 0.80 & 0.73 & 0.70 & 0.66 & 0.63 & 0.60 \\
\hline \multirow{2}{*}{ SS (\%) } & FY-4A & 6.20 & 0.40 & 3.99 & 5.05 & 6.47 & 6.62 \\
\hline
\end{tabular}

\section{Conclusions}

In this paper, we presented an algorithm to forecast very short term $(0-3 \mathrm{~h})$ surface solar irradiance using FY-4A satellite observations. The algorithm obtains the cloud motion vector (CMV) using particle image velocimetry (PIV). When the cloud index forecast values in different time horizons were made, we obtained GHI and DNI forecast values in 15-min time resolutions for 30- to 180-min time horizons based on the Heliosat-2 method. The forecast results were validated using the data from the Chengde observation station for four typical months (October 2018; January, April, and July 2019). The smart persistence (SP) model was used as a reference model. The forecast results were analyzed using the 
statistical indexes (RMSE, MAE, MBE, nRMSE, nMAE, nMBE, $R$, and SS values), as well as a scatter diagram and cumulative frequency curves.

A seasonal study was conducted that demonstrated that forecasting in July and April is more difficult than in October and January. For GHI forecasting, the proposed model using FY-4A satellite images outperformed the SP model for all forecasting horizons and seasons, with the best results being produced in October. The SS value was above 20\%. In terms of DNI forecasting, the results were worse than for GHI. The model we proposed for DNI forecasting outperformed the SP model in July and October; the skill values were about $12 \%$ and $11 \%$, respectively.

The annual performance (four typical months in total) was evaluated with the measured values. The results showed that the nRMSE values of GHI for the 30-180 min horizon were $26.78-36.84 \%$, and that the skill (SS) value reached a maximum for the $30 \mathrm{~min}$ time horizon, with a value of $20.44 \%$. The skill values were all above zero for all time horizons, confirming that the proposed algorithm is more accurate and reliable than the SP model. In terms of DNI forecasting, we observed that larger deviations occurred during steep fluctuation periods. The SS values were all above zero for all time horizons. The SS reached a maximum at the 180 -min time horizon, with a value of $6.62 \%$.

The very short term $(0-3 \mathrm{~h}) \mathrm{GHI}$ forecasting approach was proven to be accurate and reliable. The DNI forecasting was slightly better than that of the SP model, because it is complicated and sensitive to local meteorological conditions. Therefore, in the future, we will verify the model in other regions under different meteorological conditions. It is worth noting that all relevant technologies have not been specifically developed for DNI prediction, whereas DNI forecasting is derived from the GHI forecasting model.

In the future, the model needs to be further improved. A high-precision algorithm for aerosol optical thickness should be developed using FY-4A satellite observations to improve the TL calculation accuracy to improve the clear sky model accuracy. This is important for modeling the process of cloud growth and dissipation in the future, which can improve the prediction accuracy with the forecast time horizon increasing. Surface solar irradiance forecasting under hazy weather conditions is also planned, because many haze processes occur in the Beijing-Tianjin-Hebei region, which will be more meaningful for the application of the model.

Author Contributions: X.G. and L.Y. designed the research, L.Y. wrote the manuscript; J.H. and P.W. performed the field experiments; Z.L. and D.J. contributed to the investigation and software. All authors have read and agreed to the published version of the manuscript.

Funding: This work is financially supported by the National Natural Science Foundation of China (No. 41805085), the National Key Research and Development Program of China (No. 2018YFB1502800), the National Natural Science Foundation of China (No. 41675017), and the Opening Fund of Key Laboratory of Land Surface Process and Climate Change in Cold and Arid Regions, CAS (Grant No. LPCC2018006).

Acknowledgments: The authors would like to thank the National Meteorological Information Center for providing free access to the FY-4A satellite images. The authors would like to thank the Editors and Reviewers of the Sensors journal for their valuable comments.

Conflicts of Interest: The authors declare no conflict of interest.

\section{References}

1. Liu, D.; Shiroyama, H. Development of photovoltaic power generation in China: A transition perspective. Renew. Sustain. Energy Rev. 2013, 25, 782-792. [CrossRef]

2. Sinke, W.C. Development of photovoltaic technologies for global impact. Renew. Energy 2019, 138, 911-914. [CrossRef]

3. Hanfang, L.; Lin, H.; Tan, Q.; Wu, P.; Wang, C.; Gejirifu, D.; Huang, L. Research on the policy route of China's distributed photovoltaic power generation. Energy Rep. 2020, 6, 254-263. [CrossRef]

4. Barbieri, F.; Rajakaruna, S.; Ghosh, A. Very short-term photovoltaic power forecasting with cloud modeling: A review. Renew. Sustain. Energy Rev. 2017, 75, 242-263. [CrossRef]

5. Son, J.; Park, Y.; Lee, J.; Kim, H. Sensorless PV Power Forecasting in Grid-Connected Buildings through Deep Learning. Sensors 2018, 18, 2529. [CrossRef] [PubMed] 
6. Hernández-Callejo, L.; Gallardo-Saavedra, S.; Gómez, V.A. A review of photovoltaic systems: Design, operation and maintenance. Sol. Energy 2019, 188, 426-440. [CrossRef]

7. Herrería-Alonso, S.; Suárez-González, A.; Rodríguez-Pérez, M.; Rodríguez-Rubio, R.F.; López-García, C. A Solar Altitude Angle Model for Efficient Solar Energy Predictions. Sensors 2020, 20, 1391. [CrossRef] [PubMed]

8. Wild, M.; Folini, D.; Henschel, F.; Fischer, N.; Müller, B. Projections of long-term changes in solar radiation based on CMIP5 climate models and their influence on energy yields of photovoltaic systems. Sol. Energy 2015, 116, 12-24. [CrossRef]

9. Zou, L.; Wang, L.; Li, J.; Lu, Y.; Gong, W.; Niu, Y.; Ying, N. Global surface solar radiation and photovoltaic power from Coupled Model Intercomparison Project Phase 5 climate models. J. Clean. Prod. 2019, 224, 304-324. [CrossRef]

10. Barrena, C.A.; Ruiz-Arias, J.A.; Rodríguez-Benítez, F.J.; Pozo-Vázquez, D.; Tovar-Pescador, J. Short-term solar radiation forecasting by advecting and diffusing MSG cloud index. Sol. Energy 2017, 155, 1092-1103. [CrossRef]

11. Benali, L.; Notton, G.; Fouilloy, A.; Voyant, C.; Dizene, R. Solar radiation forecasting using artificial neural network and random forest methods: Application to normal beam, horizontal diffuse and global components. Renew. Energy 2019, 132, 871-884. [CrossRef]

12. Voyant, C.; Notton, G.; Kalogirou, S.; Nivet, M.-L.; Paoli, C.; Motte, F.; Fouilloy, A. Machine learning methods for solar radiation forecasting: A review. Renew. Energy 2017, 105, 569-582. [CrossRef]

13. Yeom, J.-M.; Park, S.; Chae, T.; Kim, J.-Y.; Lee, C.S. Spatial Assessment of Solar Radiation by Machine Learning and Deep Neural Network Models Using Data Provided by the COMS MI Geostationary Satellite: A Case Study in South Korea. Sensors 2019, 19, 2082. [CrossRef] [PubMed]

14. Wang, P.; Van Westrhenen, R.; Meirink, J.F.; Van Der Veen, S.; Knap, W. Surface solar radiation forecasts by advecting cloud physical properties derived from Meteosat Second Generation observations. Sol. Energy 2019, 177, 47-58. [CrossRef]

15. Caldas, M.; Alonso-Suárez, R. Very short-term solar irradiance forecast using all-sky imaging and real-time irradiance measurements. Renew. Energy 2019, 143, 1643-1658. [CrossRef]

16. Kühnert, J.; Lorenz, E.; Heinemann, D. Satellite-Based Irradiance and Power Forecasting for the German Energy Market. In Solar Energy Forecasting and Resource Assessment; Academic Press: Cambridge, MA, USA, 2013; pp. 267-297.

17. Escrig, H.; Batlles, F.J.; Alonso-Montesinos, J.; Baena, F.; Bosch, J.; Salbidegoitia, I.; Burgaleta, J. Cloud detection, classification and motion estimation using geostationary satellite imagery for cloud cover forecast. Energy 2013, 55, 853-859. [CrossRef]

18. Zhai, H.; Zhang, H.; Zhang, L.; Li, P. Cloud/shadow detection based on spectral indices for multi/hyperspectral optical remote sensing imagery. ISPRS J. Photogramm. Remote Sens. 2018, 144, 235-253. [CrossRef]

19. Nonnenmacher, L.; Coimbra, C.F. Streamline-based method for intra-day solar forecasting through remote sensing. Sol. Energy 2014, 108, 447-459. [CrossRef]

20. Gallucci, D.; Romano, F.; Cersosimo, A.; Cimini, D.; Di Paola, F.; Gentile, S.; Geraldi, E.; LaRosa, S.; Nilo, S.T.; Ricciardelli, E.; et al. Nowcasting Surface Solar Irradiance with AMESIS via Motion Vector Fields of MSG-SEVIRI Data. Remote. Sens. 2018, 10, 845. [CrossRef]

21. Ayet, A.; Tandeo, P. Nowcasting solar irradiance using an analog method and geostationary satellite images. Sol. Energy 2018, 164, 301-315. [CrossRef]

22. Rosiek, S.; Alonso-Montesinos, J.; Batlles, F. Online 3-h forecasting of the power output from a BIPV system using satellite observations and ANN. Int. J. Electr. Power Energy Syst. 2018, 99, 261-272. [CrossRef]

23. Gao, J.; Chen, J.; Tian, X. Ensemble-learning-based Cloud Phase Classification Method for FengYun-4 Remote Sensing Images. Infrared Technol. 2020, 42, 68-74.

24. Liu, Y.; Xia, J.; Shi, C.-X.; Hong, Y. An Improved Cloud Classification Algorithm for China's FY-2C Multi-Channel Images Using Artificial Neural Network. Sensors 2009, 9, 5558-5579. [CrossRef]

25. Yang, L.; Gao, X.; Li, Z.; Jia, D. Nowcasting of Surface Solar Irradiance Using Feng Yun-4 Satellite Observations over China. Remote. Sens. 2019, 11, 1984. [CrossRef]

26. Rigollier, C.; Bauer, O.; Wald, L. On the clear sky model of the ESRA—European Solar Radiation Atlas-With respect to the heliosat method. Sol. Energy 2000, 68, 33-48. [CrossRef] 
27. Rigollier, C.; Lefèvre, M.; Wald, L. The method Heliosat-2 for deriving shortwave solar radiation from satellite images. Sol. Energy 2004, 77, 159-169. [CrossRef]

28. Zhang, J.; Zheng, Y. The flexibility pathways for integrating renewable energy into China's coal dominated power system: The case of Beijing-Tianjin-Hebei Region. J. Clean. Prod. 2020, 245, 118925. [CrossRef]

29. Gueymard, C.A.; Ruiz-Arias, J.A. Validation of direct normal irradiance predictions under arid conditions: A review of radiative models and their turbidity-dependent performance. Renew. Sustain. Energy Rev. 2015, 45, 379-396. [CrossRef]

30. Ruiz-Arias, J.A.; Gueymard, C.A. Worldwide inter-comparison of clear-sky solar radiation models: Consensus-based review of direct and global irradiance components simulated at the earth surface. Sol. Energy 2018, 168, 10-29. [CrossRef]

31. Sun, X.; Bright, J.M.; Gueymard, C.A.; Acord, B.; Wang, P.; Engerer, N.A. Worldwide performance assessment of 75 global clear-sky irradiance models using Principal Component Analysis. Renew. Sustain. Energy Rev. 2019, 111, 550-570. [CrossRef]

32. Behar, O.; Sbarbaro, D.; Marzo, A.; Gonzalez, M.T.; Vidal, E.F.; Moran, L. Critical analysis and performance comparison of thirty-eight (38) clear-sky direct irradiance models under the climate of Chilean Atacama Desert. Renew. Energy 2020, 153, 49-60. [CrossRef]

33. Ineichen, P. Validation of models that estimate the clear sky global and beam solar irradiance. Sol. Energy 2016, 132, 332-344. [CrossRef]

34. Ineichen, P. Conversion function between the Linke turbidity and the atmospheric water vapor and aerosol content. Sol. Energy 2008, 82, 1095-1097. [CrossRef]

35. Liu, Y.; Lin, A.-W.; Qin, W.-M.; He, L.-J.; Li, X. Spatial-temporal Distribution of Aerosol Optical Depth and Its Main Influence Types in China During 1990-2017. Environ. Sci. 2019, 40, 2572-2581.

36. Zheng, F.; Zhou, Z.; Liu, Y.; Zuo, X.; Zhu, W. Temporal and spatial distribution characteristics of long-term aerosol optical depth in north China plain based on MODIS data. J. Henan Univ. (Nat. Sci.) 2019, 49, 450-458.

37. Guo, W. Quantitative Analysis of Spatial-Temporal Characteristics and Driving Forces of Terrestrial Aerosols in China in Nearly a Decade. Master's Thesis, Xinjiang University, Ürümqi, China, 2019.

38. Guo, C. Retrieval of Aerosol Optical Depth in Shanghai Using Remotely Sensed Data of Chinese High Resolution Satellites. Master's Thesis, East China Normal University, Shanghai, China, 2018.

39. Yang, J.; Li, Z.; Chen, X.; Li, B.; Hou, W.; Zhao, S.; Ge, B.; Ma, Y.; Zhang, Y. Retrieval system of aerosol optical depth based on high spatio-temporal resolution satellite data. J. Atmos. Environ. Opt. 2017, 13, 112-120.

40. Fan, K. Inversion of Aerosol Optical Depth in Beijing-Tianjin-Hebei Region Based on GF4 Satellite Data. Master's Thesis, YanShan University, Qinhuangdao, China, 2019.

41. Alonso-Montesinos, J.; Batlles, F.; Bosch, J. Beam, diffuse and global solar irradiance estimation with satellite imagery. Energy Convers. Manag. 2015, 105, 1205-1212. [CrossRef]

42. Mouhamet, D.; Tommy, A.; Primerose, A.; Laurent, L. Improving the Heliosat-2 method for surface solar irradiation estimation under cloudy sky areas. Sol. Energy 2018, 169, 565-576. [CrossRef]

43. Albarelo, T.; Marie-Joseph, I.; Primerose, A.; Seyler, F.; Wald, L.; Linguet, L. Optimizing the Heliosat-II Method for Surface Solar Irradiation Estimation with GOES Images. Can. J. Remote Sens. 2015, 41, 86-100. [CrossRef]

44. Bueno, L.C.; Casanova-Mateo, C.; Sanz-Justo, J.; Salcedo-Sanz, S. Machine learning regressors for solar radiation estimation from satellite data. Sol. Energy 2019, 183, 768-775. [CrossRef]

45. Trentmann, J.; Pfeifroth, U. Algorithm Theoretical Basis Document Meteosat Climate Data Records of Surface Radiation SARAH-2. (2.2); Satellite Application Facility on Climate Monitoring (CM SAF). 2017; Available online: https://icdc.cen.uni-hamburg.de/fileadmin/user_upload/icdc_Dokumente/EUMETSAT-CMSAF/SAF_ CM_DWD_ATBD_METEOSAT_HEL_2_2.pdf (accessed on 2 May 2020).

46. Skartveit, A.; Olseth, J.A.; Tuft, M.E. An hourly diffuse fraction model with correction for variability and surface albedo. Sol. Energy 1998, 63, 173-183. [CrossRef]

47. Mori, N.; Chang, K.-A. Introduction to Mpiv, User Manual and Program. Available online: http://www. oceanwave.jp/softwares/mpiv/ (accessed on 2 May 2020).

48. Gallucci, D.; Romano, F.; Cimini, D.; Di Paola, F.; Gentile, S.; LaRosa, S.; Nilo, S.T.; Ricciardelli, E.; Ripepi, E.; Viggiano, M.; et al. Improvement of Hourly Surface Solar Irradiance Estimation Using MSG Rapid Scanning Service. Remote Sens. 2019, 11, 66. [CrossRef] 
49. Kleissl, J. Solar Energy Forecasting and Resource Assessment; Academic Press: Cambridge, MA, USA, 2013; pp. 171-194.

50. Dong, J.; Olama, M.M.; Kuruganti, T.; Melin, A.M.; Djouadi, S.M.; Zhang, Y.; Xue, Y. Novel stochastic methods to predict short-term solar radiation and photovoltaic power. Renew. Energy 2020, 145, 333-346. [CrossRef]

51. Voyant, C.; Soubdhan, T.; Lauret, P.; David, M.; Muselli, M. Statistical parameters as a means to a priori assess the accuracy of solar forecasting models. Energy 2015, 90, 671-679. [CrossRef]

52. Márquez, R.; Coimbra, C.F. Proposed Metric for Evaluation of Solar Forecasting Models. J. Sol. Energy Eng. 2012, 135, 011016. [CrossRef]

53. Letu, H.; Yang, K.; Nakajima, T.Y.; Ishimoto, H.; Nagao, T.M.; Riedi, J.; Baran, A.J.; Ma, R.; Wang, T.; Shang, H.; et al. High-resolution retrieval of cloud microphysical properties and surface solar radiation using Himawari-8/AHI next-generation geostationary satellite. Remote Sens. Environ. 2020, 239, 111583. [CrossRef]

54. Xingxing, G.; Hailin, G.; Yan, C.; Lei, Z.; Wu, Z. Spatiotemporal characteristics of aerosols and its effects on cloud and precipitation during summer over typical regions in China. J. Meteorol. Environ. 2020, 36, 11-20.

55. Zhao, J.; Xu, H.; Kong, X.; Guo, J.; Xu, J.; Yu, W. Estimating Surface Direct Radiation Effect of Aerosol Based on MODIS and AERONET Data. Chin. J. Agrometeorol. 2018, 39, 693-701.

(C) 2020 by the authors. Licensee MDPI, Basel, Switzerland. This article is an open access article distributed under the terms and conditions of the Creative Commons Attribution (CC BY) license (http://creativecommons.org/licenses/by/4.0/). 